\title{
O NARRADOR E O ESPAÇO EM EDGAR ALLAN POE E JEAN EPSTEIN
}

\section{THE NARRATOR AND THE SPACE IN EDGAR ALLAN POE AND JEAN EPSTEIN}

Laura Lopes de Oliveira ${ }^{1}$

UNESP - Universidade Estadual Paulista (FCLAr)

RESUMO: Este artigo pretende analisar o narrador, o espaço e os recursos cinematográficos em "The fall of the house of Usher" (1839), de Edgar Allan Poe, e "La chute de la Maison Usher" (1928), de Jean Epstein.

PALAVRAS-CHAVE: Narrador; Espaço; Edgar Allan Poe; Jean Epstein.

ABSTRACT: The aim of this article is to analyze the role of the narrator, the space and the cinematographic resources in "The fall of the house of Usher" (1839) by Edgar Allan Poe and "La chute de la Maison Usher" (1928) by Jean Epstein.

KEYWORDS: Narrator; Space; Edgar Allan Poe; Jean Epstein.

\section{Literatura e cinema}

Os estudos sobre adaptação de textos literários para o cinema propõem diversas formas de abordagem dessa prática. Considerada como um tipo de tradução, e não uma réplica fiel do texto-origem, a adaptação fílmica pode ser considerada um ato criativo que transforma, de alguma forma, alguns elementos do texto literário - como a descrição, a ordem dos eventos, a narração etc - em equivalentes do cinema: o close-up, a edição, o plano de câmera etc. Podemos considerar que essas transformações conectam a teoria do cinema à da narrativa, pois no plano narratológico a configuração do enredo fílmico é similar à do enredo textual.

Sobre essa questão, Jacques Aumont, na obra A estética do filme (1995), afirma que "Por definição, o narrativo é extra-cinematográfico, pois se refere tanto ao teatro, ao romance quanto simplesmente à conversa cotidiana [...]" (AUMONT, 1995, p. 96). Mas, conquanto os procedimentos de narração tenham surgido antes do advento do cinema, o teórico ainda sustenta que "Esses sistemas de narração operam com outros nos filmes [...]" (AUMONT, 1995, p. 96). Por essa razão, torna-se possível localizar elementos da narrativa literária na análise fílmica. Do mesmo modo, Vanoye e Goliot-Lété, em Ensaio sobre a análise fílmica (1994), abordam o diálogo entre literatura e cinema ao citar Marc Vernet, que

\footnotetext{
${ }^{1}$ Mestranda em Estudos Literários pela Universidade Estadual Paulista “Júlio de Mesquita Filho", campus de Araraquara.
} 
"[...] retoma a tripartição [...] narrativa / narração / história-diegese para aplicá-la ao filme." (VANOYE, 1994, p. 40).

A partir dessa relação e atentando para a questão do modo como se arquiteta um relato, pretendemos fazer uma análise comparativa do trecho final do conto "The fall of the house of Usher", de Edgar Allan Poe (cuja tradução de José Paulo Paes, em 1958, é "A queda da casa de Usher"), e da sequência final de sua adaptação fílmica, "La chute de la Maison Usher", de Jean Epstein, verificando os tipos de transformações narratológicas que essa adaptação produz, por meio de recursos e procedimentos cinematográficos, e a construção do espaço em ambos os meios.

\section{Narrador e espaço}

No conto "The fall of the house of Usher" - publicado pela primeira vez em setembro de 1839, na Burton's Gentleman's Magazine - o relato do narrador é uma característica que se destaca, pois este se apresenta no enredo como testemunha e amigo de Roderick Usher, sem revelar seu nome próprio. Esse personagem recebe um convite de Roderick para passar alguns dias em sua casa. O motivo da permanência é o pedido de Usher pela presença do narrador, seu amigo, a quem diz sofrer de um mal físico e de uma perturbação mental, agravados pela suposta morte da irmã gêmea, Lady Madeline.

De acordo com as descrições dessa testemunha, o espaço é triste e sombrio. Nos primeiros dias em que permanece por lá, o narrador nos revela as excentricidades da doença de seu amigo de infância, como a intolerância a certos sons e a sensibilidade extrema do paladar, e o aparente falecimento de Madeline, cujo corpo é colocado em um caixão localizado na parte subterrânea da casa. Com o passar dos dias, o estado de saúde mental de Roderick se agrava ao mesmo tempo em que o narrador tem a impressão de que fatos estranhos acontecem naquele lugar. Essa sensação aumenta quando o dono da residência declara ao visitante que Madeline foi enterrada viva e permanece em pé, atrás da porta, como se voltasse dos mortos. Nesse momento, Madeline entra no aposento onde estão os outros personagens e desfalece sobre seu irmão. Percebendo que os dois corpos caídos estão sem vida, o narrador, assustado, foge da residência, até que esta desmorona e desaparece no fundo do pântano.

No decorrer dessa diegese, a descrição dos eventos se passa pelo olhar do personagem testemunha, ou seja, do narrador homodiegético. Sendo assim, tomamos conhecimento dos eventos por meio da percepção desse narrador, já que este expõe suas impressões acerca da aparência moribunda de Roderick, da doença de Madeline: "Um rosto de cor cadavérica" (POE, 1958, p. 149), "O mal de lady Madeline desafiara por muito tempo a habilidade dos médicos.” (POE, 1958, p. 151), do caráter sombrio do cenário, entre outros aspectos.

Percebe-se, então, que o espaço é construído, predominantemente, a partir da focalização do homodiegético, o qual sugere que a descrição da residência de Roderick seja "melancólica Casa de Usher" (POE, 1958, p. 145). Isso seria mais pelo fato de o narrador ser o detentor de um sentimento que o faz enxergar o objeto dessa maneira do que pelo aspecto "real" da casa, que poderia ser outro. Dessa forma, esse personagem teria organizado o discurso para evidenciar suas impressões, como acontece quando este compara as janelas da casa a dois olhos possivelmente humanos: 
Olhei para a cena que se abria diante de mim - para a casa simples e para a simples paisagem do domínio - para as paredes frias - para as janelas paradas como olhos vidrados - para algumas moitas de junças - e para uns troncos alvacentos de árvores mortas - com uma enorme depressão mental que só posso comparar, com alguma propriedade, com os momentos que se sucedem ao despertar de um fumador de ópio [...]. (POE, 1958, p. 145-146)

O que indicaria o aspecto particular do relato, isto é, a aparência das janelas é descrita de acordo com a percepção do amigo de Roderick, que desde o início insere as próprias divagações e sentimentos nas descrições. Da mesma maneira acontece no último fragmento do conto, em que o narrador, sozinho na parte externa da casa, relata o desmoronamento da casa e expõe, simultaneamente, suas impressões diante de tal destruição:

Daquele quarto e daquela casa, eu fugi espantado. A tempestade continuava desencadeada, com toda a sua fúria, quando me vi finalmente atravessando o velho caminho pavimentado. De repente, surgiu ao longo do caminho uma luz estranha, e eu me voltei para ver donde poderia ter saído uma claridade tão insólita, pois atrás de mim só havia a mansão com suas sombras. O resplendor vinha de uma lua no ocaso, grande e cor de sangue, que agora brilhava vivamente através daquela fenda antes apenas perceptível, da qual eu disse que se estendia desde o telhado do edifício, fazendo zigue-zague, até o alicerce. Enquanto eu olhava, esta fenda rapidamente se alargou houve uma rajada mais impetuosa da ventania - o globo inteiro do satélite invadiu de repente o campo de minha visão - meu cérebro sofreu um como desfalecimento quando vi que as grossas paredes ruíam, despedaçando-se houve um longo e tumultuoso estrondo, com mil vozes de água - e a profunda e sombria lagoa aos meus pés fechou-se funebremente por sobre os destroços da "Casa de Usher". (POE, 1958, p. 161-162)

Nota-se que mesmo o olhar objetivo é contaminado pela subjetividade, pois o personagem parece exagerar o que vê exteriormente quando orienta o relato por meio das próprias impressões. O verbo "fugi" intensifica o que poderia ser apenas um abandono, e o espanto que invade sua mente o acompanha até o exterior da mansão, influenciando o modo como vê a destruição desta: "luz estranha", "claridade insólita", "grande e cor de sangue", "rajada mais impetuosa da ventania", "longo e tumultuoso estrondo", compõem a descrição do desmoronamento da mansão e reiteram a característica particular da narração. Junta-se a esse aspecto a descrição do desaparecimento da casa dos Usher, em que "longo e tumultuoso estrondo", "mil vozes de água", "profunda e sombria lagoa aos meus pés" mostram que o narrador é o responsável pela construção e manutenção do espaço.

Na narrativa cinematográfica, diferentemente, o amigo de Roderick Usher não ocupa lugar decisivo no enredo. Essa distinção é visível em razão da predominância da focalização da câmera a captar o personagem Usher (no começo e no meio do filme), a casa e a natureza que circunda o solar, dividindo o ponto de vista com o amigo de Usher. No trecho fílmico selecionado, os três personagens - Roderick, Madeline (aqui, esposa de Usher) e o amigo - tentam abandonar o solar que começa a desmoronar. Durante a fuga, Roderick parece arrastar Madeline para fora do local, uma vez que esta, como no conto, havia ressurgido de um estado que a deixou aparentemente morta. Juntos e já na parte externa do solar, o casal e o amigo lutam contra as rajadas violentas, ao mesmo tempo que observam o desmoronamento e a destruição da casa. Há nessa sequência a presença constante de uma fumaça como índice de um incêndio provocado pela queda de um raio, misturada à neblina que envolve o ambiente. 
Como possibilidade abstrata, poderíamos dizer que a neblina é um elemento de reforço do caráter sombrio do filme que, junto com os personagens e suas expressões faciais, imprime dramaticidade à película. Aqui, a câmera objetiva parece esconder o amigo, vestido com um casaco escuro, por meio de um jogo de luz que o coloca na sombra.

No primeiro fragmento da sequência, o plano geral expõe a casa e o que a cerca: árvores mortas, galhos secos, a nevoa e as sombras que a envolvem; em seguida, temos a escadaria imponente e suas correntes grossas em plano médio, sugerindo o domínio do local sobre as ações dos personagens. Os elementos que compõem esse cenário contribuem para a formação do aspecto lúgubre do longa-metragem, reafirmando que o espaço muitas vezes torna-se um personagem na trama. Vemos, então, o amigo de costas para a câmera e em plano mais aproximado, seguido de um plano médio em que aparece o quadro com a imagem de Madeline coberta pela fumaça/neblina; nesse momento, ainda que tomado de um plano mais próximo, o personagem é encoberto pela fumaça, o que mostra seu envolvimento na trama, vivenciando os fatos naquele momento. O que está ao redor do amigo e do quadro é imperceptível, entretanto, isto não deixa de sugerir a presença de algo, aumentando o poder de suspense e lugubridade da obra e estimulando a imaginação do receptor. Nesse sentido, o que não vemos (mas imaginamos) também torna-se elemento relevante para criar o sombrio.

As tomadas internas e externas começam a se interpor, isto é, em um momento vemos o solar sendo destruído por dentro, em outro, por fora: o plano médio mostra a escadaria pegando fogo; em primeiro plano, vemos alguns galhos de árvores mortas e a fumaça/neblina que começa a impedir a visão plena do espaço, o que corrobora a ideia imaginar o que não se vê claramente; Roderick e Madeline, em plano de conjunto, tentam, com dificuldade, abandonar o local. Nota-se que não é possível distinguir as expressões do casal, fator que evidencia o espaço e a ação da natureza em detrimento dos personagens. Ademais, a imagem externa da casa, em plano de conjunto, acentua a relevância do solar de Usher no enredo. Tem-se, dessa maneira, um plano secundário para os personagens. Pode-se dizer que o solar ganha o protagonismo nessa cena, pois os personagens se misturam ao espaço: Madeline está vestida de branco e Usher, seu marido, em uma considerável parte da sequência, está com uma blusa branca. Dessa forma, o branco das roupas é similar ao da fumaça/neblina, camuflando-os no cenário e colocando-os em igual situação de destruição, isto é, cai o solar, cai, metaforicamente, o casal.

Essa semelhança entre os personagens e os elementos que compõem o espaço se mostra repetidamente. No alto da escadaria, Madeline e Roderick, praticamente em contra plongée, caminham para o lado direito do quadro e logo se camuflam em meio à fumaça. Depois, um primeiro plano expõe o quadro com a imagem de Madeline, que se movimenta, como se ali houvesse vida; entretanto, o fogo começa a destruir o quadro e, consequentemente, Madeline. Há nesse plano novamente a sugestão de destruição do casal, uma vez que o quadro representa Roderick - que o pintou - e a imagem, Madeline.

Vê-se que alguns recursos técnicos utilizados por Epstein também são estilísticos, o que o coloca na vanguarda do impressionismo francês. Como exemplo, tem-se em plano médio e no canto direito da tela os três personagens que descem a escadaria. Por meio dessa ação, começam a se aproximar da câmera, entretanto, se confundem na fumaça branca antes que o espectador possa perceber suas expressões. Há então um corte para mostrar novamente, e em primeiro plano, o quadro tomado pelo fogo. Através desses planos, pode-se dizer que os componentes visuais, como os objetos e o cenário, se sobrepõem aos personagens e suas ações: a fumaça não apenas esconde os personagens, mas os iguala aos componentes visuais por meio de uma camuflagem, dando a impressão de que estes, como o solar, começam a ruir; o quadro com a imagem de Madeline dá a impressão de que é a própria 
personagem feminina sendo destruída, visto que esta se movimenta na pintura. Pode-se dizer que essas impressões surgem em razão da montagem, visto que a fumaça, se exposta isoladamente, não comporia um sentido, mas quando vemos os personagens encobertos por essa fumaça dá-se inicio à revelação de um sentido percebido pelo receptor, pois a junção desses dois detalhes gera um resultado, um produto. Da mesma maneira aconteceria se na tela do quadro constasse apenas a imagem de Madeline: seria somente uma pintura isolada, entretanto, os planos justapostos, nos quais vemos a pintura em movimento e o fogo que a consome, dão um sentido aos fragmentos de filme. Sobre a montagem, Eisenstein (2002, p. 18) diz:

[...] cada fragmento de montagem já não existe mais como algo nãorelacionado, mas como uma dada representação particular do tema geral, que penetra igualmente todos os fotogramas. A justaposição desses detalhes parciais em uma dada estrutura de montagem cria e faz surgir aquela qualidade geral em que cada detalhe teve participação e que reúne todos os detalhes num todo, isto é, naquela imagem generalizada, mediante a qual o autor, seguido pelo espectador, apreende o tema.

Nesse sentido, as imagens desse modo de fazer cinema contam mais que as palavras: os intertítulos são raros, mas o que se destaca é o significado do componente visual e a exteriorização dos sentimentos por meio de recursos cinematográficos, como o retardamento do movimento (slow motion) utilizado para demonstrar o sofrimento no momento em que Usher e Madeline, já no exterior da casa, tentam se afastar da destruição. Nessa sequência final, os planos apresentam duração curta, em contrapartida, a movimentação dos atores é lenta. Em plano de conjunto, os três personagens ainda tentam sair da casa. É uma ação lenta, tanto do ponto de vista dos movimentos como da quantidade de planos que os mostra na parte interna do local. Essa ação, contudo, se intercala mais rapidamente com outros fragmentos de filme, o que confere maior dramaticidade à ação, ao mesmo tempo que transforma a tentativa de Usher de tirar a esposa daquele local em algo angustiante, além de expor a impotência dos personagens diante da fúria da natureza. Essa montagem de pouco mais de 40 planos parece gerar informação sobre a destruição da residência e de seus moradores, além de intercalar planos internos e externos, o que revela o caos dentro e fora da casa, pois este parece acompanhar os personagens em seu destino aparentemente fatal, como várias vezes é metaforizado no filme.

Cabe ressaltar aqui o papel da trilha sonora, semelhante às que compõem cenários fantasmagóricos, ou mesmo oníricos. Além de reforçar o tom sombrio do filme de Epstein, a trilha também dá continuidade à sequência fílmica, repleta de cortes. O caráter fantasmagórico dos fenômenos sonoros servem como um elemento de montagem e carregam a ideia de que os personagens se arrastam durante a fuga, o que reforça a sensação de angústia provocada pelo slow motion. Sobre esse aspecto fala Marcel Martin:

Enquanto a imagem de um filme é uma sequência de fragmentos, a trilha sonora restabelece de certo modo a continuidade, tanto ao nível da simples percepção quanto ao da sensação estética; [...] o papel da música é primordial como fator de continuidade sonora ao mesmo tempo material e dramática. (MARTIN, 2003, p.114)

Mas vale notar que mesmo os cortes fazem parte dessa continuidade, visto que determinam a duração do plano, e este, por sua vez, dialoga com o plano seguinte. Essa 
justaposição de planos, essa montagem, cria o sentido do trecho fílmico. De acordo com Martin:

A montagem (ou seja, a progressão dramática do filme, em suma) obedece, assim, exatamente a uma lei de tipo dialético: cada plano comporta um elemento (apelo ou ausência) que encontra resposta no plano seguinte: a tensão psicológica (atenção ou interrogação) criada no espectador deve ser satisfeita pela sequência dos planos. A narrativa fílmica surge então como uma série de sínteses parciais (cada plano é uma unidade, mas uma unidade incompleta) que se encadeiam numa perpétua superação dialética. (MARTIN, 2003, p.139)

Temos agora o amigo em plano médio, semelhando um tronco de árvore; um plano de conjunto da casa; o casal, em plano mais aproximado, está no canto esquerdo da tela, como se tomasse distância da natureza em revolta; o amigo, do mesmo modo que Roderick e Madeline, se aproxima da câmera até ficar em primeiro plano. Nesse momento, podemos observar os rostos dos personagens, sem, contudo, deixar de perceber a obscuridade que não permite uma observação minuciosa das expressões. Nos fragmentos finais da sequência reconhecemos mais os personagens - ora em primeiro plano, ora em plano médio - que já se encontram na parte externa do solar. Embora haja uma identificação, os elementos que compõem o espaço interferem no reconhecimento pleno dos personagens, pois estes se mesclam com a fumaça/neblina, com os móveis, com as árvores. Ademais, há o trabalho de iluminação. A obscuridade prevalece por meio de um jogo de luz que coloca as figuras na contraluz e sempre com um nevoeiro que as esconde ou as torna menos importantes que o espaço, o qual ganha maior relevância, afinal, é tema da obra a queda da casa de Usher. No plano final, esse aspecto se reitera: não vemos mais os personagens na tela, mas o que restou do objeto, isto é, da casa.

Vale, pois, ressaltar que o trecho literário escolhido para servir de comparação com a cena selecionada, mostra um narrador sozinho perante uma catástrofe - a morte dos irmãos e a destruição da casa. Seria a iteração da importância de tal personagem na trama, pois a descrição coloca em evidência suas impressões particulares acerca dos acontecimentos exteriores à casa, mostrando que o leitor necessita desse personagem para conhecer os eventos. Além disso, há a sinestesia do fragmento:

Enquanto eu olhava, esta fenda rapidamente se alargou - houve uma rajada mais impetuosa da ventania - o globo inteiro do satélite invadiu de repente o campo de minha visão - meu cérebro sofreu um como desfalecimento quando vi que as grossas paredes ruíam, despedaçando-se - houve um longo e tumultuoso estrondo, com mil vozes de água [...]. (POE, 1958, p. 161-162)

Nesse excerto, o leitor tem a impressão de ouvir a explosão da lua e o estampido prolongado causado pelo desmoronamento da casa. Em "A tempestade continuava desencadeada, com toda a sua fúria, quando me vi finalmente atravessando o velho caminho pavimentado" (POE, 1958, p. 161), as gotas que parecem bater violentamente no corpo do narrador provocam a sensação tátil do ledor. Vê-se que essas sensações são oriundas do olhar particular do homodiegético. No filme, o avivamento dos sentidos do espectador provém dos recursos cinematográficos - slow motion, fusões, sobreposições etc - e da utilização do espaço como elemento criador de significados. 
Pode-se dizer que existe a preponderância da montagem ideológica nessa sequência fílmica: em todo o fragmento, como já observado, o movimento dos seres fictícios é lento, ao passo que a duração dos planos é curta. Essa diferença de "velocidades" sugere a luta árdua dos personagens para fugir daquele local, ao mesmo tempo que indica a superioridade da força da natureza. Marcel Martin considera que esse tipo de montagem:

[...] serve para designar as aproximações de planos destinadas a comunicar ao espectador um ponto de vista, um sentimento ou uma ideia mais ou menos precisos e gerais. (MARTIN, 2003, p.152)

Esse aspecto confere poeticidade à sequência, característica marcante do cinema impressionista francês, se considerarmos, também, as metáforas visuais que compõem os planos.

No longa de Epstein, Usher e a câmera são fundamentais para gerar dramaticidade, pois, quando ocorrem os primeiros planos do rosto de Usher, vemos como o ator consegue expressões faciais super dramáticas. Entretanto, nessa cena final, os efeitos de imagem e o enquadramento, em maior grau que os personagens, são elementos fundamentais para gerar a impressão de angústia e o aspecto obscuro. O contrário se vê no conto, em que o narrador imprime essa dramaticidade por meio das próprias impressões.

\section{REFERÊNCIAS}

AUMOnt, J. et al. A estética do filme. 3a.ed. Trad. Marina Appenzeller. Campinas: Papirus, 1995.

EISENSTEIN, S. O sentido do filme. Trad. Teresa Ottoni. Rio de Janeiro: Jorge Zahar, 2002. LA CHUTE de la maison Usher. Direção: Jean Epstein. França : Films J. Epstein, 1928. 1 DVD (66 min), son., color.

MARTIN, M. A linguagem cinematográfica. Trad. Paulo Neves ; revisão técnica Sheila Schvartzman. São Paulo : Brasiliense, 2003.

POE, E. A. Histórias extraordinárias. Trad. José Paulo Paes. São Paulo: Cultrix, 1958.

VANOYE, F.; GOLIOT-LÉTÉ, A. Ensaio sobre análise fílmica. Trad. Marina Appenzeller. Campinas: Papirus, 1994.

Recebido em: 15/08/12

Aprovado em: 07/11/12 